\title{
Selective spectrofluorimetric method for the determination of perindopril erbumine in bulk and tablets through derivatization with dansyl chloride
}

Amir Alhaj Sakur ${ }^{1}$, Tamim Chalati ${ }^{2}$ and Hanan Fael ${ }^{1 *}$

\begin{abstract}
Background: Perindopril erbumine is an antihypertensive, which belongs to the category of angiotensin-converting enzyme inhibitors (ACE inhibitors) that inhibit the conversion of angiotensin I to angiotensin II.

Methods: A new, selective, and sensitive spectrofluorimetric method was developed for the determination of perindopril erbumine based on the reaction with dansyl chloride in alkaline medium to give a highly fluorescent derivative which was measured at $496 \mathrm{~nm}$ after excitation at $340 \mathrm{~nm}$ in dichloromethane. The reaction conditions were studied and optimized.
\end{abstract}

Results: Under the optimum conditions, the fluorescence intensity was linear over a concentration range of 1.0 to $21.0 \mu \mathrm{g} / \mathrm{mL}\left(R^{2}=0.9997\right)$ with a detection limit of $0.242 \mu \mathrm{g} / \mathrm{mL}$. In order to validate the method, the results were compared with those obtained by a high performance liquid chromatography method.

Conclusions: The proposed method was successfully applied to the analysis of perindopril erbumine in pure form and tablets with good precision and accuracy as revealed by $t$ - and $F$ tests. The mechanism of the reaction has also been discussed.

Keywords: Perindopril erbumine; Dansyl chloride; Derivatization; Spectrofluorimetry

\section{Background}

Perindopril erbumine (PDE) is the tert-butylamine salt of perindopril, which is the ethyl ester prodrug of the angiotensin-converting enzyme (ACE) inhibitor, perindoprilat. Perindopril erbumine is chemically described as 2-methylpropan-2-amine (2S,3aS,7aS)-1-[(2S)-2-[[(1S)1-(ethoxycarbonyl) butyl] amino] propanoyl]octahydro$1 \mathrm{H}$-indole-2-carboxylate, Figure 1. Its empirical formula is $\mathrm{C}_{19} \mathrm{H}_{32} \mathrm{~N}_{2} \mathrm{O}_{5} \mathrm{C}_{4} \mathrm{H}_{11} \mathrm{~N}$.

Perindopril erbumine belongs to the category of angiotensin-converting enzyme inhibitors (ACE inhibitors) that inhibit the conversion of angiotensin I to angiotensin II. Perindopril erbumine is indicated for the treatment of hypertension; this effect appears to result primarily from

\footnotetext{
* Correspondence: hananfael@hotmail.com

${ }^{1}$ Department of Analytical Chemistry, Faculty of Pharmacy, University of

Aleppo, Aleppo, Syria

Full list of author information is available at the end of the article
}

the inhibition of circulating and tissue ACE activity thereby reducing angiotensin II formation and decreasing vasoconstriction. Perindopril erbumine is also indicated for patients with congestive heart failure [British National Formulary BNF 2014].

Literature reported only few analytical methods for the determination of PDE in its bulk, dosage forms and human plasma, such as high performance liquid chromatography (Raju and Rao 2011; Zaazaa et al. 2013; Riyaz et al. 2012; Chaudhary et al. 2010; Jogia et al. 2010; Joseph et al. 2011; Prajapati et al. 2011a), HPLC-MS (Jaina et al. 2006 and Nirogi et al. 2006), high performance thin layer chromatography (Dewani et al. 2011), and spectrophotometry (Neelam et al. 2012; Rahman et al. 2012; Prajapati et al. 2011b). However, the chromatographic methods were found to have certain drawbacks, such as the expensive instrumentation and high analysis cost. Spectrophotometric methods, on the other 


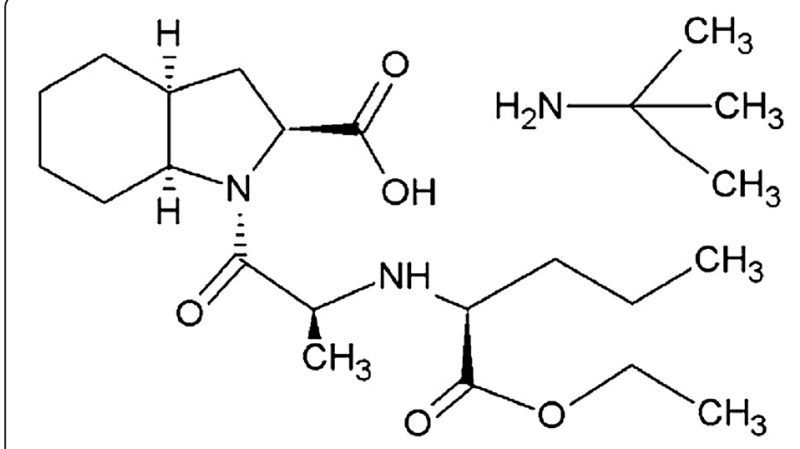

Figure 1 Perindopril erbumine structure.

hand, are not such sensitive methods in spite of being simple and economic technique. Therefore, it is still significant to develop a new, simple and sensitive method for the determination of perindopril erbumine.

There seems to be no reports on determination of such important drug, perindopril erbumine, using spectrofluorimetry, which shows several advantages such as high sensitivity, low detection limit, ease of use, and less time consumption comparing with other analytical methods.

Dansyl chloride (DNS) is known to react with primary and secondary amines, phenolic and alcoholic hydroxyl groups, and carboxylic acid groups (Bartzatt 2003). DNS has been used as a fluorogenic reagent for the determination of many pharmaceutical compounds (Aydoğmuş et al. 2012; Abd El Ghaffar et al. 2011; Abdel Fattah et al. 2010; Ulu 2011; Karasakal and Ulu 2013).

This paper describes, for the first time, the derivatization of PDE with dansyl chloride. The proposed method is sensitive, accurate, simple, and selective. It was applied for the determination of PDE in bulk and as well as in pharmaceutical preparations.

\section{Methods}

\section{Chemicals and materials}

All reagents and solvents were of analytical grade.

Perindopril erbumine (ROLABO outsourcing S.L., Spain) stock standard solution of $1.0 \mathrm{mg} / \mathrm{mL}$ was prepared in deionized (DI) water. This solution was freshly prepared at time of study. A series of working standard solutions were prepared by diluting aliquots of stock standard solution with DI water. Dansyl chloride (5-dimethylaminonaphthalene-1-sulphonyl chloride) was purchased from Merck, Germany. Solution of DNS was freshly prepared at $1.0 \mathrm{mg} / \mathrm{mL}$ in acetonitrile. Bicarbonate buffer $(0.1 \mathrm{M})$ solution was prepared in DI water and adjusted to $\mathrm{pH} 9.5$ with $0.1 \mathrm{M}$ sodium hydroxide. Bicarbonate buffer solution was kept in refrigerator and used within about 5 days.
Perindopril erbumine tablets, Revosyl ${ }^{\circ}$ (Ibn Alhaytham Pharma. Industries Co., Syria) and Neomeril ${ }^{\circ}$ (Oubari Pharma, Syria) containing 4 and $8 \mathrm{mg}$, were purchased from local medical stores.

\section{Instrumentation}

Fluorescence spectra and measurements were obtained using fluorescence spectrophotometer F-2700 (Hitachi, Japan) equipped with xenon lamp. Excitation and emission wavelengths were set at 340 and $496 \mathrm{~nm}$, respectively. The slit widths for excitation and emission monochromators were fixed at $5 \mathrm{~nm}$. All measurements were performed in $1-\mathrm{cm}$ quartz cell at room temperature.

Chromatographic (HPLC) analysis was performed on (Agilent 1200 series, Agilent Technologies, Germany) apparatus equipped with UV detector, autosampler, and column oven. Chromatographic separation was achieved on C18 column $(5 \mu \mathrm{m}, 100 \times 4.6 \mathrm{~mm})$.

\section{Derivatization procedure}

A $100 \mu \mathrm{L}$ of PDE working standard solutions equivalent to a final concentration of 1.0 to $21.0 \mu \mathrm{g} / \mathrm{mL}$ was transferred into a series of 2-mL micro tubes that contain $100 \mu \mathrm{L}$ of $\mathrm{pH} 9.5$ bicarbonate buffer solution. A $300 \mu \mathrm{L}$ of dansyl chloride solution was then added, and solution was mixed vigorously; then, tubes were kept in dry block heater at $40^{\circ} \mathrm{C}$ for $30 \mathrm{~min}$. The tubes were then cooled, and the dansyl derivative was extracted three times with $1.5 \mathrm{~mL}$ of dichloromethane by a vortex mean. The organic layer was separated after centrifuging at 5,000 rpm for $1 \mathrm{~min}$ to ensure separation of organic-aqueous layers. The combined dichloromethane extracts were adjusted to $5 \mathrm{~mL}$ with the same solvent. The fluorescence intensity of the resulting solution was measured at $496 \mathrm{~nm}$ after excitation at $340 \mathrm{~nm}$ against reagent blank that had been treated similarly.

\section{Determination of stoichiometric relationship}

The composition ratio of the derivative product was determined using Job's continuous variation method and molar ratio method. In Job's method, equimolar solutions $\left(2.26 \times 10^{-3} \mathrm{M}\right)$ of perindopril erbumine and dansyl chloride were mixed in which the total moles of reactants were kept at $4.53 \times 10^{-7}$ moles. The volume of reaction phase was kept constant at $300 \mu \mathrm{L}$; then, steps were completed as described under the derivatization procedure. A plot of fluorescence intensities against the mole fraction of reagent was then constructed.

On the other hand, the molar ratio method was carried out. Increasing volumes of dansyl chloride were added to a fixed volume of drug solution. The obtained fluorescence intensities were then plotted against reagent molar ratio. 


\section{Procedure for pharmaceutical samples}

Ten individual tablets were weighed and pulverized carefully. An accurately weighed amount of the powder equivalent to $8 \mathrm{mg}$ of PDE was transferred into $25-\mathrm{mL}$ volumetric flask and dissolved in $20 \mathrm{~mL}$ of bicarbonate buffer. The content of the flask was sonicated for $20 \mathrm{~min}$ then diluted to volume with bicarbonate buffer. Portion of this solution was centrifuged at 5,000 rpm for $10 \mathrm{~min}$. Suitable aliquot of the supernatant was then transferred into micro tubes that contain $100 \mu \mathrm{L}$ of DI water. A 300 $\mu \mathrm{L}$ of dansyl chloride solution was then added, and procedure was continued as mentioned above.

\section{Results and discussion}

\section{Fluorescence spectra}

Perindopril erbumine contains two amino groups and can therefore react with dansyl chloride in alkaline medium to give a strongly fluorescent product. On contrast, a reagent blank gave a negligible fluorescence signal at the chosen excitation and emission wavelengths. Under the described experimental conditions, the excitation spectra was obtained showing two maximum excitation wavelength at 260 and $340 \mathrm{~nm}$, respectively. The excitation wavelength of 340 was employed, and emission spectra were obtained showing emission wavelength maxima at $496 \mathrm{~nm}$ (Figure 2).

\section{Optimization of reaction conditions}

\section{Effect of $\mathrm{pH}$}

Effect of $\mathrm{pH}$ on the derivatization reaction was investigated using three different buffers in the alkaline region. Bicarbonate, phosphate, and borate buffers were studied. Buffers with amino groups such as tris and triethylamine were excluded, since they react with DNS reagent. The reaction was carried out initially at lab temperature for $30 \mathrm{~min}$. The highest fluorescence intensity was obtained using pH 9.5 bicarbonate and borate buffer (Figure 3).

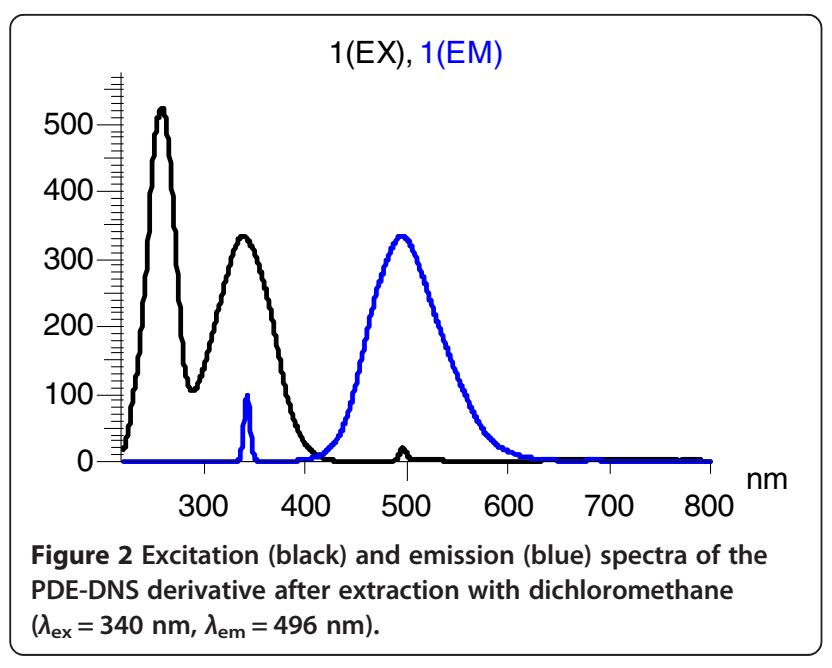

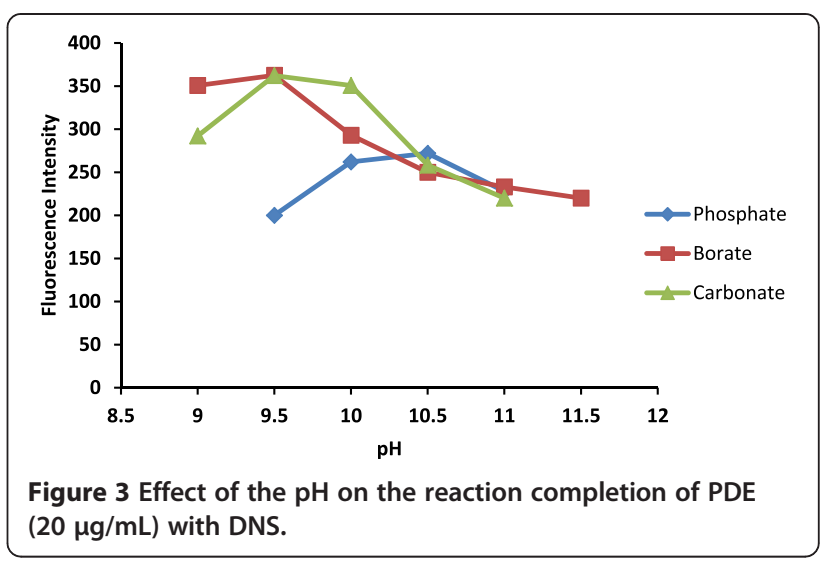

Following that, in the study of temperature effect, bicarbonate and borate buffer were tested to find out which buffer is more appropriate.

\section{Effect of time and temperature}

In this study, the reaction between PDE and dansyl chloride was performed using $\mathrm{pH} 9.5$ bicarbonate buffer at different temperatures $\left(20^{\circ} \mathrm{C}, 30^{\circ} \mathrm{C}, 40^{\circ} \mathrm{C}\right.$, and $\left.50^{\circ} \mathrm{C}\right)$ for various time intervals $(10,20,30,45$, and $60 \mathrm{~min})$. As it is seen in Figure 4, the derivatization reaction was found to be completed after $30 \mathrm{~min}$ at $40^{\circ} \mathrm{C}$. Subsequently, borate buffer was tested at $40^{\circ} \mathrm{C}$ for $30 \mathrm{~min}$ and bicarbonate buffer was preferred over it.

\section{Effect of buffer volume and concentration}

Under the above described experimental conditions, the volume required of $0.1 \mathrm{M}$ bicarbonate buffer $(\mathrm{pH}$ 9.5) was tested. As shown in Figure 5, a volume of $100 \mu \mathrm{L}$ has given a maximum fluorescence intensity; thus, it was chosen to proceed the reaction. In addition, the buffer concentration was investigated at three different molarities $(0.05,0.1$, and $0.2 \mathrm{M})$. It was found that $0.1 \mathrm{M}$ has given the best results; thus, it was used for the next experiments.

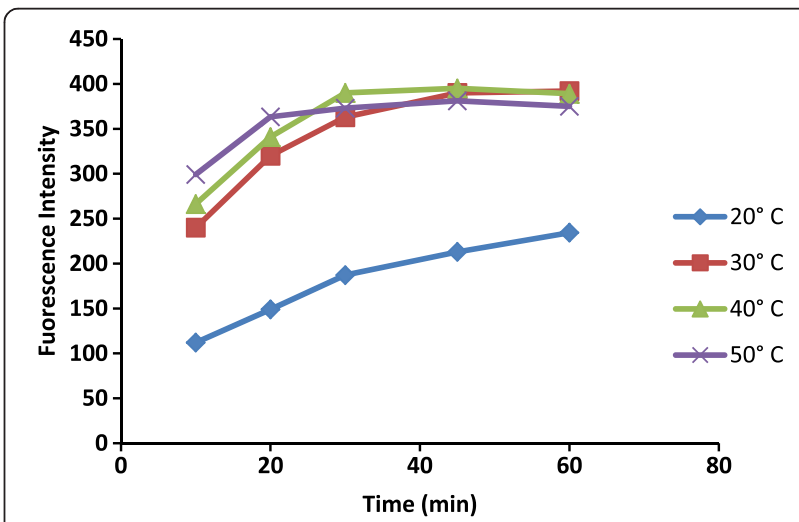

Figure 4 Effect of the temperature and time on the reaction completion of PDE $(20 \mu \mathrm{g} / \mathrm{mL})$ with DNS. 


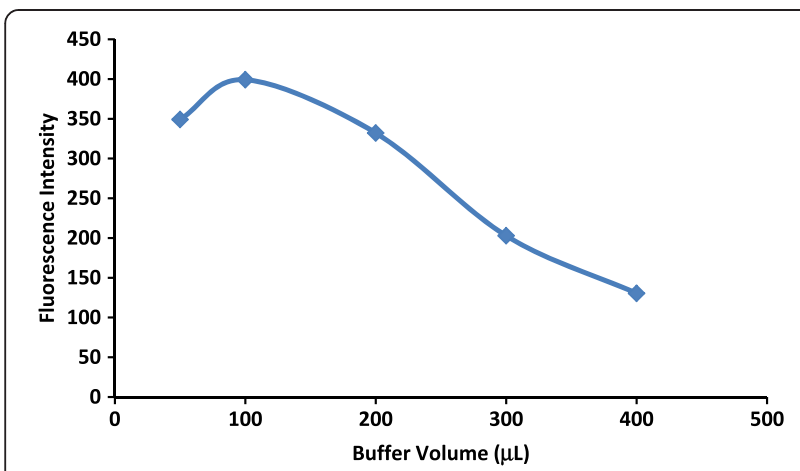

Figure 5 Effect of the volume added of $0.1 \mathrm{M}$ bicarbonate buffer at $\mathrm{pH} 9.5$ on the derivatization reaction of PDE $(20 \mu \mathrm{g} / \mathrm{mL})$.

\section{Effect of dansyl chloride volume}

The influence of the volume of dansyl chloride solution was examined by addition of different volumes of $0.1 \%$ $\mathrm{w} / \mathrm{v}$ reagent in the range of 50 to $500 \mu \mathrm{L}$ (Figure 6). A maximum and steady fluorescence intensity was obtained when more than $200 \mu \mathrm{L}$ of dansyl chloride solution was utilized. Thus, a fixed volume of $300 \mu \mathrm{L}$ was used in the optimal procedure

\section{Effect of extraction solvent}

The aqueous reaction medium contains, in addition to the derivatization product, a highly fluorescent secondary product: dansyl hydroxide (Bartzatt 2003). In order to avoid the interference of this compound, an extraction step has been performed, so that the polar dansyl hydroxide remained in the aqueous phase and derivatization product moved to the immiscible organic solvent. For this purpose, different solvents including dichloromethane, chloroform, diethyl ether, and ethyl acetate were tested.

Ethyl acetate was rejected, since the blank value was very high when it was employed as an extractant. However, the highest fluorescence was obtained upon using dichloromethane (Table 1). The emission and excitation

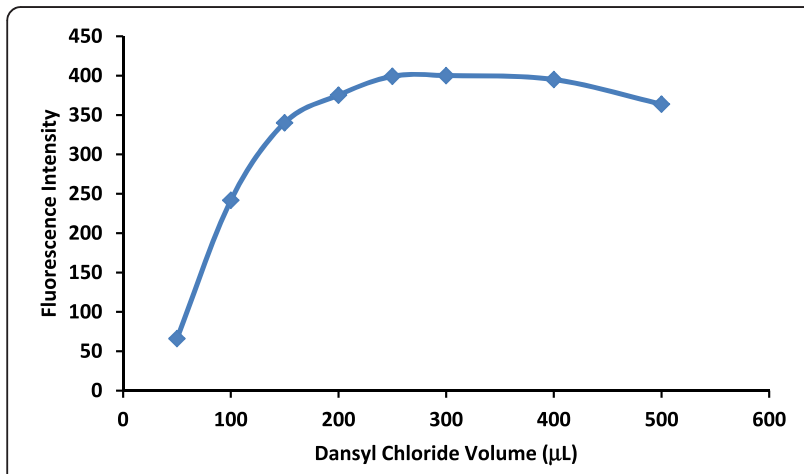

Figure 6 Effect of the volume added of $0.1 \% \mathrm{w} / \mathrm{w}$ dansyl chloride on the derivatization reaction of PDE $(20 \mu \mathrm{g} / \mathrm{mL})$.
Table 1 The maximum excitation and emission wavelengths of the PDE-DNS derivatization product and its fluorescence intensities in different organic extraction solvents

\begin{tabular}{lccc}
\hline Extraction solvent & $\boldsymbol{\lambda}_{\mathrm{ex}} / \boldsymbol{\lambda}_{\mathrm{em}}(\mathrm{nm})$ & \multicolumn{2}{c}{ Fluorescence intensity } \\
\cline { 3 - 4 } & & Sample & Blank \\
\hline Dichloromethane & $340 / 496$ & 540.3 & 3.6 \\
Chloroform & $337 / 494$ & 432.7 & 3.5 \\
Diethyl ether & $330 / 489$ & 391.5 & 3.0 \\
Ethyl acetate & $323 / 459$ & 876.9 & 636.3 \\
\hline
\end{tabular}

aPDE concentration $=20 \mu \mathrm{g} / \mathrm{mL}$.

spectra of derivatization product of perindopril erbumine in dichloromethane are shown in Figure 2.

\section{Stoichiometric relationship of the reaction}

Under the described conditions, the stoichiometry of the reaction between the drug and DNS was studied by Job's method of continuous variation and molar ratio method. As shown in Figures 7 and 8, the stoichiometry of the reaction was found to be 2:1 ratio (DNS/drug), confirming that one molecule of PDE reacts with two molecules of DNS. Perindopril erbumine contains a secondary amine in the perindopril moiety and a primary aliphatic amine in the erbumine molecule. In alkaline medium, these amine groups become more basic, and thus the electron pairs on the nitrogen atoms are free and could be involved easily in nucleophilic reactions. The reaction may be illustrated by the attack of these nucleophilic groups into the sulfonyl chloride group of DNS. A schematic proposal of the reaction pathway is given in Scheme 1 .

\section{Validation of the proposed method}

\section{Linearity}

Under the optimum experimental conditions, standard calibration curve was constructed at eight concentration levels $(n=5)$. The correlation coefficient was 0.9997 , indicating good linearity over the concentration range of 1.0 to $21.0 \mu \mathrm{g} / \mathrm{mL}$. The intercept, slope, limit of

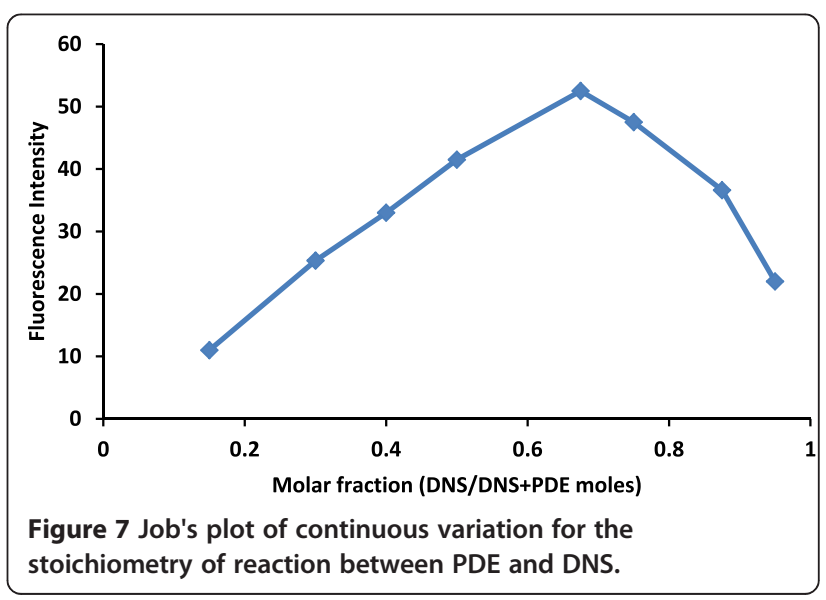




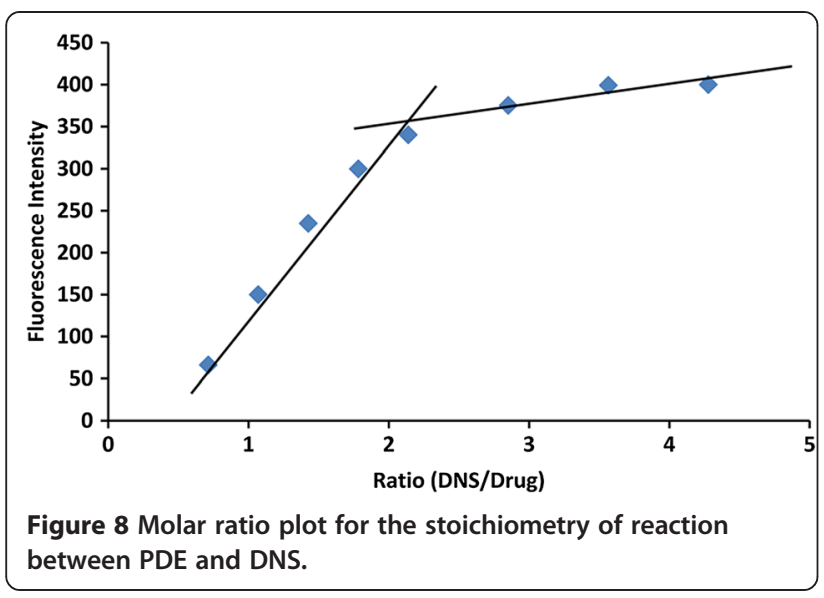

detection (LOD), and limit of quantitation (LOQ) are summarized in Table 2. LOD and LOQ values were calculated according to $\mathrm{ICH}$ Q2B using the following equations:

$$
\begin{aligned}
& \text { LOQ }=10 \sigma / S \\
& \text { LOD }=3.3 \sigma / S
\end{aligned}
$$

where $\sigma$ is the standard deviation of intercept of regression line and $S$ is the slope of the calibration curve (Table 2).

\section{Selectivity}

The effects of some common excipients used in pharmaceutical preparations were studied by analyzing solutions containing suggested amounts of each excipient. Frequently
Table 2 Statistics and analytical parameters of PDE determination

\begin{tabular}{lc}
\hline Parameter & Result \\
\hline$\lambda_{\text {ex }} / \lambda_{\text {em }}(\mathrm{nm})$ & $340 / 496$ \\
Linear range $(\mu \mathrm{g} / \mathrm{mL})$ & 1.0 to 21.0 \\
Slope & 27.164 \\
Standard deviation in the slope & 0.178 \\
Intercept & 4.5958 \\
Standard deviation in the intercept & 1.992 \\
Correlation coefficient & 0.9997 \\
Limit of detection $(\mu \mathrm{g} / \mathrm{mL})$ & 0.242 \\
Limit of quantification $(\mu \mathrm{g} / \mathrm{mL})$ & 0.733 \\
\hline
\end{tabular}

encountered excipients or additives were studied such as lactose, microcrystalline cellulose (Avicel), soluble starch, polyvinylpyrrolidone (PVP k30), talc, and magnesium stearate. None of the studied excipients has given any fluorescent product. So, the proposed method is suitable for analysis of perindopril erbumine in its dosage forms and application in quality control laboratories.

\section{Precision}

The repeatability of proposed method was estimated by measuring five replicate samples of each concentration of perindopril erbumine prepared in one laboratory on the same day. The precision expressed as the relative standard deviation (RSD\%) ranged from $0.61 \%$ to $4.92 \%$ for the smallest concentration, indicating good precision (Table 3).<smiles>CCOC(=O)C1CC2CCC1N2</smiles><smiles>CC(C)C(=O)N1[C@H](C(=O)O)C[C@@H]2CCCC[C@H]21</smiles>

Alkaline medium

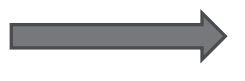<smiles>CCC[C@H](C(=O)OCC)N([C@H](C)C(=O)N1[C@H](C(=O)O)C[C@@H]2CCCC[C@H]2[C@H]1C)S(=O)(=O)c1cccc2c(N)cccc12</smiles>
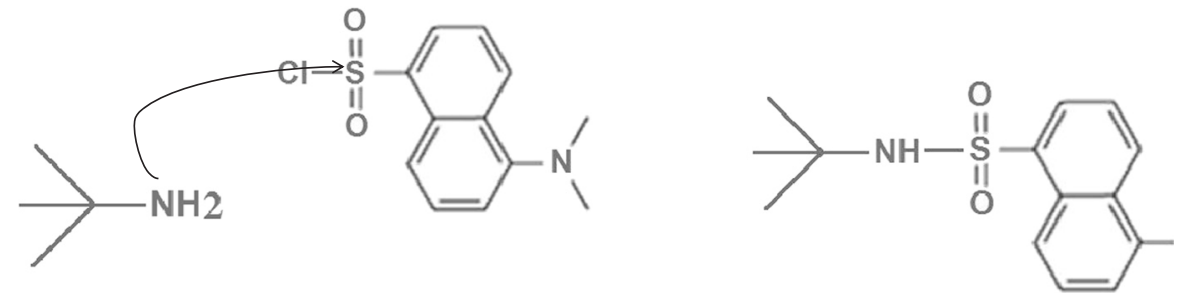

Scheme 1 Schematic illustration of reaction between PDE and DNS. 
Table 3 Precision and accuracy for determination of PDE in pure form

\begin{tabular}{|c|c|c|c|c|c|}
\hline \multicolumn{2}{|c|}{ Perindopril erbumine $(\mu \mathrm{g} / \mathrm{mL})$} & \multirow[t]{2}{*}{ SD } & \multirow[t]{2}{*}{ RSD\% } & \multirow[t]{2}{*}{ Recovery \% } & \multirow[t]{2}{*}{$t$-test ${ }^{\mathrm{b}}$} \\
\hline Taken & Found $^{\mathrm{a}}$ & & & & \\
\hline 1.00 & $0.976 \pm 0.059$ & 0.048 & 4.92 & 97.60 & 1.118 \\
\hline 2.20 & $2.195 \pm 0.074$ & 0.060 & 2.73 & 99.77 & 0.186 \\
\hline 4.50 & $4.590 \pm 0.104$ & 0.084 & 1.83 & 102.00 & 2.395 \\
\hline 6.70 & $6.733 \pm 0.118$ & 0.095 & 1.41 & 100.49 & 0.776 \\
\hline 8.70 & $8.770 \pm 0.156$ & 0.126 & 1.44 & 100.80 & 1.242 \\
\hline 11.20 & $11.169 \pm 0.125$ & 0.101 & 0.90 & 99.72 & 0.686 \\
\hline 16.80 & $16.940 \pm 0.182$ & 0.147 & 0.86 & 100.83 & 2.129 \\
\hline 21.00 & $20.930 \pm 0.160$ & 0.129 & 0.61 & 99.66 & 1.213 \\
\hline
\end{tabular}

${ }^{a}$ Average of five determination \pm confidence limit.

${ }^{\mathrm{b}}$ The tabulated $t$-value at $95 \%$ confidence limit for 4 degrees of freedom $(n=5)$ is 2.78 .

\section{Accuracy}

The proposed method was applied on the available commercial tablets that contain PDE, and recoveries are mentioned in Table 4. However, the method's accuracy is judged by (1) determining the average amount of PDE in pure form at several levels and using a significance test to compare it with actual amount $\mu$ (Harvey 2009]):

$$
t=\frac{|\bar{X}-\mu|}{S D} \sqrt{n}
$$

As shown in Table 3, the calculated $t$-value is less than tabulated $t(0.05,4)$ value $(2.78)$, and thus there are no significant differences between the taken and found concentration at $95 \%$ confidence level. Accuracy was indicated as well by analyzing the recoveries of known different amounts of PDE (Table 3) which varied from $97.60 \%$ to $102.00 \%$. (2) The method's accuracy is also judged by comparing the results obtained from the presently proposed method with those obtained from a reference method such as high performance liquid chromatography (HPLC) (Raju and Rao 2011). The obtained results were statistically compared with each other (Table 4) using $t$ - and $F$-tests. $t_{\exp }$ was calculated using the following equation (Harvey 2009):

$$
t_{\exp }=\frac{\left|\bar{X}_{A}-\bar{X}_{B}\right|}{\sqrt{\left(S_{A}^{2} / n_{A}\right)+\left(S_{B}^{2} / n_{B}\right)}}
$$

Where $\bar{X}_{A}$ and $\bar{X}_{B}$ are PDE mean values in each pharmaceutical product using the proposed and reference methods, respectively. $S$ and $n$ are the standard deviation and the number of replicate trials conducted on samples, respectively. With respect to $t$ - and $F$ tests, no significant differences were found between the calculated values of both the proposed and the reported methods at $95 \%$ confidence level.

\section{Robustness}

Robustness was investigated by evaluating the influence of minute variations in the experimental conditions such as volume of reagent $( \pm 10 \mu \mathrm{L})$, volume of bicarbonate solution $( \pm 5 \mu \mathrm{L})$, and reaction time $( \pm 5 \mathrm{~min})$. These minor changes that may happen during the analysis did not have any significant effect on fluorescence intensity of the reaction product.

\section{Application to tablets}

The proposed method was successfully applied to analysis of two different commercial tablets (Revosyl ${ }^{\circ}$ and Neomeril ${ }^{\circ}$ tablets) were labeled to contain 4 and $8 \mathrm{mg}$ of PDE. The mean recovery values were ranged from 96.50 to 104.25 , which were identical to the recoveries recorded by the reference method (HPLC) as revealed by $t$ - and $F$ test (Table 4).

\section{Comparison with reported analytical methods}

The analytical methods reported in the literature suffered from one or more disadvantages like poor sensitivity, use of expensive chemicals, and/or complicated instruments, as can be seen from Table 5. However, the proposed method was found to be more sensitive than spectrophotometric and chromatographic methods (except for LC-MS);

\begin{tabular}{|c|c|c|c|c|}
\hline \multirow[t]{2}{*}{ Tablets } & \multirow[t]{2}{*}{ Labeled amount of PDE } & \multicolumn{2}{|c|}{ 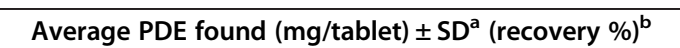 } & \multirow[t]{2}{*}{$t$ - and $F$ test } \\
\hline & & Proposed method & Reference method $^{d}$ & \\
\hline \multirow[t]{2}{*}{ Revosyl } & $4 \mathrm{mg}$ & $4.10 \pm 0.036(102.50)$ & $4.06 \pm 0.024(101.50)$ & $1.734,2.207$ \\
\hline & $8 \mathrm{mg}$ & $8.34 \pm 0.064(104.25)$ & $8.44 \pm 0.040(105.50)$ & $2.464,2.612$ \\
\hline \multirow[t]{2}{*}{ Neomeril } & $4 \mathrm{mg}$ & $3.86 \pm 0.035(96.50)$ & $3.90 \pm 0.026(97.50)$ & $1.604,1.830$ \\
\hline & $8 \mathrm{mg}$ & $7.77 \pm 0.075(97.12)$ & $7.87 \pm 0.042(98.37)$ & $2.299,3.196$ \\
\hline
\end{tabular}

Table 4 Precision and accuracy for determination of PDE in tablets

${ }^{a}$ Average and standard deviation of five determinations for the proposed method and three determinations for the reference method.

${ }^{\mathrm{b}}$ Recoveries were calculated considering the labeled amount reported by the manufacturer.

'The tabulated $t$-value at $95 \%$ confidence limit for 4 degrees of freedom $(n=5)$ is 2.78 and the tabulated $F$ value at $95 \%$ confidence limit for $(4,2)$ degrees of freedom for the proposed and reference methods, respectively, is 6.944 .

${ }^{d}$ HPLC (Raju and Rao 2011. 
Table 5 Performance characteristics of the existing methods used for the determination of PDE

\begin{tabular}{|c|c|c|c|c|c|}
\hline No & Method & Medium & Application & Linear range & Reference \\
\hline 1 & HPLC & Phosphate buffer: acetonitrile (65:35) & Tablets & 20 to $100 \mu \mathrm{g} / \mathrm{mL}$ & Raju and Rao 2011 \\
\hline 2 & HPLC & $\begin{array}{l}\text { Phosphate buffer: acetonitrile: } \\
\text { Tetrahydrofuran (60:40:0.1) }\end{array}$ & Tablets (combination with amlodipine) & 10 to $100 \mu \mathrm{g} / \mathrm{mL}$ & Zaazaa et al. 2013 \\
\hline 3 & HPLC & Phosphate buffer: acetonitrile (55:45) & Tablets (combination with amlodipine) & 16 to $96 \mu \mathrm{g} / \mathrm{mL}$ & Riyaz et al. 2012 \\
\hline 4 & HPLC & Acetonitrile: acidic water (50:50) & Tablets (combination with losartan potassium) & 1 to $30 \mu \mathrm{g} / \mathrm{mL}$ & Chaudhary et al. 2010 \\
\hline 5 & HPLC & Phosphate buffer: acetonitrile (75:25) & Dosage forms (combination with indapamide) & 24 to $56 \mu \mathrm{g} / \mathrm{mL}$ & Jogia et al. 2010 \\
\hline 6 & HPLC & Phosphate buffer: acetonitrile (60:40) & Dosage forms (combination with indapamide) & 8 to $24 \mu \mathrm{g} / \mathrm{mL}$ & Joseph et al. (2011) \\
\hline 7 & HPLC & Phosphate buffer: acetonitrile (65:35) & Tablets (combination with amlodipine) & 8 to $60 \mu \mathrm{g} / \mathrm{mL}$ & Prajapati et al. 2011a \\
\hline 8 & LC-MS/MS & - & Human plasma & 0.5 to $350 \mathrm{ng} / \mathrm{mL}$ & Jaina et al. 2006 \\
\hline 9 & LC/MS & - & Human plasma & 0.1 to $100 \mathrm{ng} / \mathrm{mL}$ & Nirogi et al. [2006] \\
\hline 10 & HPTLC & $\begin{array}{l}\text { Dichloromethane: methanol: } \\
\text { glacial acetic acid (9.5:0.5:0.1) }\end{array}$ & Dosage forms (combination with indapamide) & 1 to $5 \mu \mathrm{g} / \mathrm{band}$ & Dewani et al. 2011 \\
\hline 11 & Spectrophotometry & Chloroform & Tablets & 5 to $125 \mu \mathrm{g} / \mathrm{mL}$ & Neelam et al. 2012 \\
\hline 12 & Spectrophotometry & Dimethylsulfoxide & Tablets & 2.5 to $25 \mu \mathrm{g} / \mathrm{mL}$ & Rahman et al. 2012 \\
\hline 13 & Spectrophotometry & Methanol & Tablets (combination with amlodipine) & 4 to $12 \mu \mathrm{g} / \mathrm{mL}$ & Prajapati et al. $2011 \mathrm{~b}$ \\
\hline 14 & Spectrofluorimetry & Dichloromethane & Tablets & 1 to $21 \mu \mathrm{g} / \mathrm{mL}$ & This work \\
\hline
\end{tabular}

in addition to less time-consuming compared with HPLC methods.

\section{Conclusion}

New, simple, and sensitive spectrofluorimetric method for the determination of PDE has been successfully developed and validated. The method involved the formation of a fluorescent derivatization product resulted from the reaction of PDE with DNS in alkaline medium. The proposed method was specific, precise, and accurate with a comparable low detection limit value of $0.242 \mu \mathrm{g} / \mathrm{mL}$. The method was effectively applied for determining PDE in pure form and in tablets without any interference with the excipients. Therefore, the developed method can be suitable for routine analysis of PDE in quality control laboratories.

\section{Competing interests}

The authors declare that they have no competing interests.

\section{Authors' contributions}

HF has performed the experimental and analytical work and prepared the draft of the manuscript. The guidelines and supervision of this work was provided by AAS. AAS and TC read and modified the manuscript. All authors read and approved the final manuscript.

\section{Author details}

${ }^{1}$ Department of Analytical Chemistry, Faculty of Pharmacy, University of Aleppo, Aleppo, Syria. ${ }^{2}$ Department of Pharmaceutics, Faculty of Pharmacy, University of Aleppo, Aleppo, Syria.

Received: 10 December 2014 Accepted: 6 January 2015

Published online: 15 March 2015

\section{References}

Abd El Ghaffar ME, El Wasseef DR, El Sherbiny DT, El Ashry SM (2011) Spectrofluorimetric determination of two $\beta$ agonist drugs in bulk and pharmaceutical dosage forms via derivatization with dansyl chloride. J Anal Chem 66:476-481
Abdel Fattah LS, Mohamed TA, Taha EA (2010) Spectrofluorimetric determination of carvedilol in dosage form and spiked human plasma through derivatization with 1-dimethylaminonaphthalene-5-sulphonyl chloride. Chem Ind Chem Eng Q 16:31-38

Aydoğmuş Z, Sarı F, Ulu ST (2012) Spectrofluorimetric determination of aliskiren in tablets and spiked human plasma through derivatization with dansyl chloride. J Fluoresc 22:549-556

Bartzatt R (2003) Dansylation of aromatic, aliphatic and medicinal carboxylic acid compounds in $1 \mathrm{M} \mathrm{Na}_{2} \mathrm{CO}_{3}$ buffer. Anal Chim Acta 488:203-209

Joint Formulary Committee (2014) British National Formulary, 67th edition. British Medical Association and Royal Pharmaceutical Society of Great Britain, London

Chaudhary AB, Patel RK, Chaudhary SA (2010) Determination of losartan potassium and perindopril erbumine in tablet formulations by reversedphase HPLC. International Journal of ChemTech Research 2:1141-1146

Dewani MG, Bothara KG, Madgulkar AR, Damle MC (2011) Simultaneous estimation of perindopril erbumine and indapamide in bulk drug and tablet dosage form by HPTLC. International Journal of Comprehensive Pharmacy 2:1-4

Harvey D (2009). Modern analytical chemistry. Second ed., David Harvey.

Jaina DS, Subbaiah G, Sanya M, Pande UC, Shrivastav P (2006) First LC-MS/MS electrospray ionization validated method for the quantification of perindopril and its metabolite perindoprilat in human plasma and its application to bioequivalence study. J Chromatogr B 837:92-100

Jogia H, Khandelwal U, Gandhi T, Singh S, Modi D (2010) Development and validation of a stability-indicating assay method for simultaneous determination of perindopril and indapamide in combined dosage form by reversed-phase high-performance liquid chromatography. J AOAC Int 93:108-115

Joseph J, Philip B, Sundarapandian M (2011) Method development and validation for simultaneous estimation of perindopril erbumine and indapamide by RP-HPLC in pharmaceutical dosage forms. International Journal of Pharmacy and Pharmaceutical Sciences 3:288-293

Karasakal A, Ulu ST (2013) New spectrofluorimetric method for the determination of nizatidine in bulk form and in pharmaceutical preparations. Opt Spectrosc 115:306-309

Neelam S, Gopisetti J, Chandra BS (2012) Spectrophotometric analysis of perindopril erbumine in bulk and tablets using bromophenol blue. Der Pharmacia Lettre 4:159-169

Nirogi RVS, Kandikere VN, Shukla M, Mudigonda K, Maurya S, Komarneni P (2006) High-throughput quantification of perindopril in human plasma by liquid chromatography/tandem mass spectrometry: application to a bioequivalence study. Rapid Commun Mass Spectrom 20:1864-1870

Prajapati J, Patel A, Patel MB, Prajapati N, Prajapati R (2011a) Analytical method development and validation of amlodipine besylate and perindopril 
erbuminee in combine dosage form by RP-HPLC. International Journal of PharmTech Research 3:801-808

Prajapati J, Patel MB, Prajapati N, Prajapati R (2011b) Simultaneous determination of perindopril erbumine and amlodipine besylate by absorption factor method. Int J Appl Biol Pharmaceut Tech 2:230-233

Rahman N, Rahman H, Khatoon A (2012) Development of spectrophotometric method for the determination of perindopril erbumine in pharmaceutical formulations using 2, 4 dinitrofluorobenzene. J Chil Chem Soc 57:1069-1073

Raju VB, Rao AL (2011) Development and validation of new HPLC method for the estimation of perindopril in tablet dosage forms. Rasayan J Chem 4:113-116

Riyaz SMD, Vasanth PM, Ramesh M, Ramesh R, Ramesh T (2012) A sensitive RP-HPLC method development and validation for the simultaneous estimation of perindopril erbumine and amlodipine besilate in tablet dosage form. International journal of chemical and life science 1:1033-1038

Ulu ST (2011) Sensitive spectrofluorimetric determination of tizanidine in pharmaceutical preparations, human plasma and urine through derivatization with dansyl chloride. Luminescence: The Journal of Biological and Chemical Luminescence. doi:10.1002/bio.1367

Zaazaa HE, Abbas SS, Essam HA, El Bardicy MG (2013) Validated chromatographic methods for determination of perindopril and amlodipine in pharmaceutical formulation in the presence of their degradation products. J Chromatogr Sci $51: 533-543$

\section{Submit your manuscript to a SpringerOpen ${ }^{\circ}$ journal and benefit from:}

- Convenient online submission

- Rigorous peer review

- Immediate publication on acceptance

- Open access: articles freely available online

- High visibility within the field

- Retaining the copyright to your article

Submit your next manuscript at $\gg$ springeropen.com 